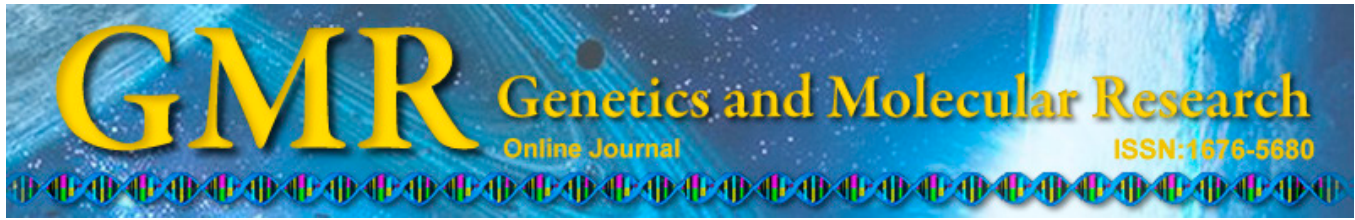

\title{
Analysis of the haplotype and linkage disequilibrium of PPAR $\gamma$ gene polymorphisms rs3856806, rs12490265, rs1797912, and rs1175543 among patients with metabolic syndrome in Kazakh of Xinjiang Province
}

\author{
S.X. Guo, H. Guo, R.L. Ma, Y.S. Ding, J.Y. Zhang, J.M. Liu, M. Zhang, \\ Q. Niu, N. Qiang, S.G. Li and C.N. Qi \\ Department of Preventive Medicine, Medical College of Shihezi University, \\ Shihezi, XinJiang, China
}

Corresponding author: S.X. Guo

E-mail: shuxiaguocn@163.com

Genet. Mol. Res. 13 (4): 8686-8694 (2014)

Received August 13, 2013

Accepted April 17, 2014

Published October 27, 2014

DOI http://dx.doi.org/10.4238/2014.October.27.9

\begin{abstract}
We investigated the relationship between haplotype and linkage disequilibrium of the PPAR $\gamma$ gene polymorphisms rs3856806, rs12490265, rs1797912, and rs1175543 and metabolic syndrome (MS) in the Kazakh people of Xinjiang Province. For PPAR $\gamma$, rs3856806, rs12490265, rs1797912, and rs1175543 genotypes were detected in 489 subjects (including $245 \mathrm{MS}$ patients and 244 controls) using matrixassisted laser desorption-ionization time-of-flight mass spectrometry. Frequencies ofrs3856806T, rs12490265A,rs1797912C, andrs1175543G alleles in MS patients were significantly lower than those of controls [rs3856806T allele: 12.53 vs $17.01 \%(\mathrm{P}=0.044)$, rs12490265A allele: 31.84 vs $38.52 \%(\mathrm{P}=0.029)$, rs $1797912 \mathrm{C}$ allele: 35.31 vs $43.24 \%$ ( $\mathrm{P}$ $=0.011)$, rs 1175543G allele: 40.61 vs $47.54 \%(\mathrm{P}=0.029)]$. Significant
\end{abstract}


linkage disequilibrium was observed between the PPAR $\gamma$ rs1797912 and rs1175543 polymorphisms as well as between the rs12490265 and rs 1175543 polymorphisms. A total of 14 haplotypes were found. Patients with rs3856806T, rs12490265A, rs1797912C, and rs1175543G were observed 0.267 times more frequently [ $95 \%$ confidence interval $=$ $0.126-0.566$ ] than those with rs3856806C, rs12490265G, rs1797912A, and rs1175543A, respectively. The PPAR $\gamma$ gene polymorphisms rs3856806, rs12490265, rs1797912, and rs1175543 were associated with MS in Kazakh subjects. Very strong linkage disequilibrium was found between the PPAR $\gamma$ rs 1797912 and rs 1175543 polymorphisms as well as between the rs12490265 and rs1175543 polymorphisms. AGCC and GAAT haplotypes may serve as protective factors against MS. The rs3856806T, rs12490265A, rs1797912C, and rs1175543G alleles may enhance the protective effect of MS.

Key words: Kazakh; Metabolic syndrome; PPAR $\gamma$; Polymorphism; Haplotype; Linkage disequilibrium

\section{INTRODUCTION}

Metabolic syndrome (MS) is a set of clinical symptoms characterized by metabolic disorders, including obesity, insulin resistance, lipid metabolic disorder, abnormal glucose tolerance or type 2 diabetes, and high blood pressure. The prevalence of MS has increased worldwide, affecting health expenditure and becoming an increasingly important public health problem. The onset of MS shows regional, ethnic, and gender differences (Grundy et al., 2005; Gu et al., 2005; Bouguerra et al., 2006; Gavrila et al., 2011). The Kazakh people of Xinjiang Province are an ethnic group with a high risk of MS, showing a prevalence rate of $21.96 \%$ (Jiang and Xie, 2012); this value is higher than that of the Han population inhabiting the same region (Jiang and Xie, 2012). Revealing the cause of MS is important for preventing MS, cardiovascular disease, and type 2 diabetes; however, the exact etiology and pathogenesis of MS are not fully understood. MS is caused by genetic and environmental factors. Insulin resistance links the pathophysiological processes involved in MS. Previous studies have suggested that the most notable biological effect of the PPAR $\gamma$ gene is its regulation of insulin sensitivity. PPAR $\gamma$ genetic polymorphisms include rs3856806, rs 12490265, rs1797912, and rs1175543, which may be associated with MS. Differences exist among ethnicities and regions with respect to PPAR $\gamma$ gene polymorphisms; however, the results of various studies are not consistent regarding the extent in or causes of these differences $\mathrm{Hu}$ et al., 2004; Chen et al., 2006; Jaziri et al., 2006; Gaulton et al., 2008; Cho et al., 2009; Gallicchio et al., 2009; Matsuo et al., 2009; Bego et al., 2011). Because the geographical and ethnic characteristics of members of the Xinjiang population can be used to reveal the cause of MS and thus provide a theoretical basis for its underlying genetic mechanism, this study examined the relationship of the PPAR $\gamma$ rs3856806, rs12490265, rs1797912, and rs1175543 polymorphisms, their haplotypes, and linkage disequilibrium with MS in Kazakh subjects in Xinxiang. 


\section{MATERIAL AND METHODS}

\section{Subjects}

Current MS status was investigated by extracting 5692 cases from patients aged 18 years and above among Kazakh residents in Xinyuan County of Xinjiang Yili Region using the stratifying cluster sampling method. Biochemical parameters were detected. Based on the results and the 2005 International Diabetes Federation definition of MS (Alberti et al., 2005), 245 patients with MS were randomly selected as the case group. A total of 244 cases of non-MS from the same population were randomly selected as the control group using the group-matching method. This study was conducted in accordance with the Declaration of Helsinki and with approval from the Ethics Committee of Shihezi University. Written informed consent was obtained from all participants.

\section{DNA extraction}

Two hundred microliters of fasting blood was extracted from subjects. Genomic DNA was extracted from blood using a blood genomic DNA extraction kit (centrifugal columnar) obtained from Tektronix Biotechnology Co., Ltd. (Beijing, China). Extracted DNA was verified by $0.7 \%$ gel electrophoresis. A NanoDrop spectrophotometer was used to determine concentration and purity quantitatively. Purity (optical density $(\mathrm{OD})_{260} / \mathrm{OD}_{280}$ ) was between 1.7 and 2.0, and the concentration was $\geq 30 \mathrm{ng} / \mu \mathrm{L}$. Qualified DNA was diluted in autoclaved double-distilled water. The concentration was adjusted from 10 to $30 \mathrm{ng} / \mu \mathrm{L}$. Samples were stored at $-80^{\circ} \mathrm{C}$.

\section{Matrix-assisted laser desorption-ionization time-of-flight mass spectrometry (MALDI-TOF-MS)}

Primers were designed using the Mysequenom tool (www.mysequenom.com/Home) with the Assay Designer3.0 software. Pro12Ala upstream and downstream primers were 5'-ATTCCATGCTGTTATGGGTG-3' and 5'-GTGTATCAGTGAAGGAATCG-3', respectively. The C1431T upstream primer was 5'-GACAGACCTCAGACAGATTG-3', while the downstream primer was 5'-AAGACTCATGTCTGTCTCCG-3'. The final polymerase chain reaction (PCR) volume was $5 \mu \mathrm{L}$, which included $0.7 \mu \mathrm{L}$ DNA sample, $1.35 \mu \mathrm{L}$ water, $0.5 \mu \mathrm{L}$ 10X PCR buffer, $0.4 \mu \mathrm{L} \mathrm{MgCl}_{2}, 0.1 \mu \mathrm{L}$ dNTPs, $0.15 \mu \mathrm{L}$ Taq enzyme, and $1.8 \mu \mathrm{L}$ PCR amplification primer mixture. PCR conditions were as follows: $94^{\circ} \mathrm{C}$ for 4 min, denaturation at $94^{\circ} \mathrm{C}$ for $20 \mathrm{~s}$, annealing at $56^{\circ} \mathrm{C}$ for $30 \mathrm{~s}$, extension at $72^{\circ} \mathrm{C}$ for $1 \mathrm{~min}(45 \mathrm{cycles})$, and final extension at $72^{\circ} \mathrm{C}$ for $3 \mathrm{~min}$. The reaction products were stored at $4^{\circ} \mathrm{C}$. All operations were carried out in an ice bath. The same procedure was conducted for the negative controls.

PCR products were purified using shrimp alkaline phosphatase (SAP). To ensure the accuracy of single-base extension, the remaining dNTPs were removed after PCR using SAP. The final SAP reaction volume was $2.0 \mathrm{~mL}$, which included $1.53 \mu \mathrm{L}$ double-distilled water, $0.17 \mu \mathrm{L} \mathrm{10X} \mathrm{SAP} \mathrm{buffer,} \mathrm{and} 0.3 \mu \mathrm{L}$ SAP enzyme. The reaction conditions were $37^{\circ} \mathrm{C}$ for 40 min and $85^{\circ} \mathrm{C}$ for $5 \mathrm{~min}$. The reaction products were stored at $4^{\circ} \mathrm{C}$.

A single-base extension reaction (EXTEND) was conducted in a final reaction volume of $2.0 \mu \mathrm{L}$, including $0.2 \mu \mathrm{L} 5 \mathrm{X}$ iPlex buffer, $0.619 \mu \mathrm{L}$ water, $0.2 \mu \mathrm{L}$ iPlex terminator, 0.94 $\mu \mathrm{L}$ primer mix, and $0.041 \mu \mathrm{L}$ iPlex enzyme. Pro12Ala and $\mathrm{C} 1431 \mathrm{~T}$ extension primers were 5'-TCTGGGAGATTCTCCTATTGAC-3' and 5'-GTCAGACAGATTGTCACGGAACA-3', 
respectively. Reaction conditions were as follows: denaturation at $94^{\circ} \mathrm{C}$ for $30 \mathrm{~s} ; 94^{\circ} \mathrm{C}$ for $5 \mathrm{~s}$, $52^{\circ} \mathrm{C}$ for $5 \mathrm{~s}, 80^{\circ} \mathrm{C}$ for $1 \mathrm{~min}$ for 40 cycles; $52^{\circ} \mathrm{C}$ for $5 \mathrm{~s}, 80^{\circ} \mathrm{C}$ for $1 \mathrm{~min}$ for 5 cycles; $72^{\circ} \mathrm{C}$ for $3 \mathrm{~min}$. The reaction products were stored at $4^{\circ} \mathrm{C}$.

Samples were purified using resin. Mass ARRAY Nanodispenser (Sequenom, San Diego, CA, USA) was used for the purified product. The product was then transferred to a SpectroCHIP (Sequenom) and analyzed by MALDI-TOF-MS. Results were encoded using the TYPER 4.0 software (Sequenom).

\section{Statistical analysis}

The Epidata 3.02 software was used to establish a database, and the double-entry method was used for data input and logic error detection. The SPSS 17.0 statistical package was used for the chi-square test and univariate logistic regression analysis (SPSS, Inc., Chicago, IL, USA). The SHEsis software (http://analysis.bio-x.cn/myAnalysis.php) was used for haplotype analysis, and the Phase software was used for linkage disequilibrium analysis. The frequency of alleles was determined by direct counting.

\section{RESULTS}

\section{Subjects}

The Kazakh MS group included 85 male and 160 female subjects. The control group included 83 male and 161 female subjects. The gender ratio between groups was not statistically significant $\left(\chi^{2}=0.025, P=0.875\right)$. Mean ages were $42.51 \pm 9.61$ years in the MS group and $41.49 \pm 8.80$ years in the control group. No significant age difference was found between the 2 groups $(t=-1.23, \mathrm{P}=0.219)$.

\section{Genotype and allele frequency distribution}

Table 1 shows that the rs3856806, rs12490265, rs1797912, and rs1175543 polymorphism distributions in the Kazakh population were in Hardy-Weinberg equilibrium. The differences in the 4-site genotype and allele frequencies between the MS and control groups were statistically significant $(\mathrm{P}<0.05$; Table 2$)$.

\section{Linkage disequilibrium and haplotype analysis}

Linkage disequilibrium analysis showed that the rs1797912 and rs 1175543 polymorphisms $\left(D^{\prime}=0.9149 / 0.9024, R_{2}=0.6680 / 0.6845\right)$ and $\mathrm{rs} 12490265$ and $\mathrm{rs} 1175543$ polymorphisms $\left(D^{\prime}=0.8069 / 0.8439, R_{2}=0.4447 / 0.4925\right)$ showed strong linkage disequilibrium (Table 3 ).

Haplotype analysis showed that the four PPAR $\gamma$ loci, rs12490265, rs1175543, rs 1797912, and rs3856806, yielded 14 haplotypes. Six of the haplotypes, AAAT (rs12490265A, rs1175543A, rs1797912A, and rs3856806T), GACT, AACC, AGCT, AGAT, and GGAC were less than four cases in both MS and control groups, haplotype frequencies were less than $0.8 \%$ (data not shown). The GAAC haplotype frequency distributions in the MS and control groups were 47.76 and $37.50 \%$, respectively. Compared with the common haplotypes GAAC AGCC 
[odds ratio $(\mathrm{OR})=0.568,95 \%$ confidence interval $(\mathrm{CI})=0.414-0.779]$ and GAAT $(\mathrm{OR}=$ $0.563,95 \% \mathrm{CI}=0.352-0.901)$, other haplotypes may reduce the risk of MS among the Kazakh people $(\mathrm{P}>0.05$; Table 4).

Table 1. Genotype distributions of four Kazakh PPAR $\gamma$ gene polymorphisms analyzed using the HardyWeinberg equilibrium test.

\begin{tabular}{|c|c|c|c|c|c|}
\hline \multirow[t]{2}{*}{ Sites } & \multirow[t]{2}{*}{ Genotype } & \multicolumn{2}{|c|}{$\operatorname{MS}(\mathrm{N}=245)$} & \multicolumn{2}{|c|}{ Control $(\mathrm{N}=244)$} \\
\hline & & Observations (\%) & Expected (\%) & Observations (\%) & Expected (\%) \\
\hline \multirow[t]{5}{*}{ rs3856806 } & $\mathrm{CC}$ & $193(78.78)$ & $188(76.65)$ & $167(68.44)$ & $168(68.88)$ \\
\hline & $\mathrm{CT}$ & $43(17.55)$ & $53(21.80)$ & $71(29.10)$ & $69(28.23)$ \\
\hline & TT & $9(3.67)$ & $4(1.55)$ & $6(2.46)$ & $7(2.89)$ \\
\hline & $\chi^{2}$ & 3.030 & & 0.108 & \\
\hline & $\mathrm{P}$ & 0.220 & & 0.947 & \\
\hline \multirow[t]{5}{*}{ rs1175543 } & AA & $73(29.80)$ & $86(35.10)$ & $55(22.54)$ & $67(27.52)$ \\
\hline & GA & $145(59.18)$ & $120(48.98)$ & $146(59.84)$ & $122(49.88)$ \\
\hline & GG & $27(11.02)$ & $39(15.92)$ & $43(17.62)$ & $55(22.60)$ \\
\hline & $\chi^{2}$ & 5.603 & & 4.799 & \\
\hline & $\mathrm{P}$ & 0.061 & & 0.091 & \\
\hline \multirow[t]{5}{*}{ rs1797912 } & AA & $100(40.82)$ & $103(41.85)$ & $79(32.38)$ & $79(32.22)$ \\
\hline & $\mathrm{CA}$ & $117(47.75)$ & $112(45.68)$ & $119(48.77)$ & $120(49.08)$ \\
\hline & $\mathrm{CC}$ & $28(11.43)$ & $30(12.47)$ & $46(18.85)$ & $45(18.70)$ \\
\hline & $\chi^{2}$ & 0.222 & & 0.015 & \\
\hline & $\stackrel{n}{\mathrm{P}}$ & 0.895 & & 0.992 & \\
\hline \multirow[t]{5}{*}{ rs 12490265} & GG & $103(42.04)$ & $114(46.46)$ & $80(32.78)$ & $92(37.71)$ \\
\hline & $\mathrm{AG}$ & $128(52.25)$ & $106(43.40)$ & $140(57.38)$ & $116(47.54)$ \\
\hline & AA & $14(5.71)$ & $25(10.14)$ & $24(9.84)$ & $36(14.75)$ \\
\hline & $\chi^{2}$ & 5.729 & & 5.487 & \\
\hline & $\stackrel{\sim}{\mathrm{P}}$ & 0.057 & & 0.064 & \\
\hline
\end{tabular}

$\mathrm{MS}=$ metabolic syndrome.

Table 2. Risk analysis between PPAR $\gamma$ gene genotypes, alleles, and Kazakh metabolic syndrome (MS).

\begin{tabular}{|c|c|c|c|c|c|c|c|c|c|}
\hline \multirow[t]{2}{*}{ Sites } & \multirow[t]{2}{*}{ Genotype/Allele } & \multicolumn{2}{|c|}{ MS } & \multicolumn{2}{|c|}{ Control } & \multirow[t]{2}{*}{$\chi^{2}$} & \multirow[t]{2}{*}{$\mathrm{P}$} & \multirow[t]{2}{*}{ OR } & \multirow[t]{2}{*}{$95 \% \mathrm{CI}$ for $\mathrm{OR}$} \\
\hline & & $\mathrm{N}$ & $\%$ & $\mathrm{~N}$ & $\%$ & & & & \\
\hline \multirow[t]{6}{*}{ rs 3856806} & $\mathrm{CC}$ & 193 & 78.78 & 167 & 68.44 & & & 1.000 & \\
\hline & $\mathrm{CT}$ & 43 & 17.55 & 71 & 29.10 & 8.607 & 0.003 & 0.524 & $0.340-0.807$ \\
\hline & TT & 9 & 3.67 & 6 & 2.46 & 0.235 & 0.628 & 1.298 & $0.453-3.722$ \\
\hline & $\mathrm{CT} / \mathrm{TT}$ & 52 & 21.22 & 77 & 31.56 & 6.721 & 0.010 & 0.584 & $0.388-0.879$ \\
\hline & $\mathrm{C}$ & 429 & 87.55 & 405 & 82.99 & 4.048 & 0.044 & 1.000 & \\
\hline & $\mathrm{T}$ & 61 & 12.45 & 83 & 17.01 & & & 0.694 & $0.485-0.992$ \\
\hline \multirow[t]{6}{*}{ rs12490265 } & GG & 103 & 42.04 & 80 & 32.78 & & & 1.000 & \\
\hline & $\mathrm{AG}$ & 128 & 52.25 & 140 & 57.38 & 3.162 & 0.075 & 0.710 & $0.487-1.036$ \\
\hline & AA & 14 & 5.71 & 24 & 9.84 & 4.774 & 0.029 & 0.453 & $0.220-0.932$ \\
\hline & $\mathrm{AG} / \mathrm{AA}$ & 142 & 57.96 & 164 & 67.22 & 4.470 & 0.034 & 0.673 & $0.465-0.972$ \\
\hline & G & 334 & 68.16 & 300 & 61.48 & 4.796 & 0.029 & 1.000 & \\
\hline & A & 156 & 31.84 & 188 & 38.52 & & & 0.745 & $0.573-0.970$ \\
\hline \multirow[t]{6}{*}{ rs1797912 } & AA & 100 & 40.82 & 79 & 32.38 & & & 1.000 & \\
\hline & $\mathrm{CA}$ & 117 & 47.75 & 119 & 48.77 & 1.614 & 0.204 & 0.777 & $0.526-1.147$ \\
\hline & $\mathrm{CC}$ & 28 & 11.43 & 46 & 18.85 & 6.807 & 0.009 & 0.481 & $0.276-0.837$ \\
\hline & $\mathrm{CA} / \mathrm{CC}$ & 145 & 59.18 & 165 & 67.62 & 3.752 & 0.053 & 0.694 & $0.480-1.005$ \\
\hline & A & 317 & 64.69 & 277 & 56.76 & 6.450 & 0.011 & 1.000 & \\
\hline & $\mathrm{C}$ & 173 & 35.31 & 211 & 43.24 & & & 0.716 & $0.554-0.927$ \\
\hline \multirow[t]{6}{*}{ rs1175543 } & AA & 73 & 29.80 & 55 & 22.54 & & & 1.000 & \\
\hline & GA & 145 & 59.18 & 146 & 59.84 & 1.848 & 0.174 & 0.748 & $0.492-1.137$ \\
\hline & GG & 27 & 11.02 & 43 & 17.62 & 6.169 & 0.013 & 0.473 & $0.261-0.858$ \\
\hline & GA/GG & 172 & 70.20 & 189 & 77.46 & 3.330 & 0.068 & 0.686 & $0.457-1.029$ \\
\hline & A & 291 & 59.39 & 256 & 52.46 & 4.762 & 0.029 & 1.000 & \\
\hline & G & 199 & 40.61 & 232 & 47.54 & & & 0.755 & $0.586-0.972$ \\
\hline
\end{tabular}


Table 3. Linkage disequilibrium analysis of 4 polymorphic loci of the PPAR $\gamma$ gene between the Kazakh metabolic syndrome (MS) group and the control group.

\begin{tabular}{|c|c|c|c|c|}
\hline Site & $\mathrm{rs} 12490265$ & rs 1175543 & rs1797912 & rs3856806 \\
\hline rs12490265 & - & $0.8069 / 0.8439$ & $0.4729 / 0.5770$ & $0.4615 / 0.4737$ \\
\hline rs 1175543 & $0.4447 / 0.4925$ & - & $0.9149 / 0.9024$ & $0.2877 / 0.0387$ \\
\hline rs1797912 & $0.1914 / 0.2739$ & $0.6680 / 0.6845$ & - & $0.2422 / 0.0239$ \\
\hline rs3856806 & $0.0141 / 0.0288$ & $0.0081 / 0.0003$ & $0.0046 / 0.0001$ & - \\
\hline
\end{tabular}

Above diagonal $=D^{\prime}$-linkage disequilibrium coefficient. Below diagonal $=R^{2}$-correlation coefficient. For each coefficient, the MS group is displayed first followed by the control group.

\begin{tabular}{|c|c|c|c|c|c|c|c|c|}
\hline \multirow[t]{2}{*}{ Haplotype } & \multicolumn{2}{|c|}{ MS } & \multicolumn{2}{|c|}{ Control } & \multirow[t]{2}{*}{$\chi^{2}$} & \multirow[t]{2}{*}{$\mathrm{P}$} & \multirow[t]{2}{*}{ OR } & \multirow[t]{2}{*}{$95 \% \mathrm{CI}$ for OR } \\
\hline & $\mathrm{N}$ & $\%$ & $\mathrm{~N}$ & $\%$ & & & & \\
\hline GAAC & 234 & 47.76 & 183 & 37.50 & & & 1.000 & \\
\hline AGCC & 106 & 21.63 & 146 & 29.92 & 12.409 & 0.000 & 0.568 & $0.414-0.779$ \\
\hline GGCC & 41 & 8.37 & 29 & 5.94 & 0.147 & 0.701 & 1.106 & $0.662-1.847$ \\
\hline GAAT & 36 & 7.35 & 50 & 10.25 & 5.826 & 0.016 & 0.563 & $0.352-0.901$ \\
\hline AGAC & 31 & 6.33 & 25 & 5.12 & 0.012 & 0.915 & 0.970 & $0.553-1.700$ \\
\hline GGCT & 16 & 3.27 & 23 & 4.71 & 3.279 & 0.070 & 0.544 & $0.279-1.060$ \\
\hline AAAC & 10 & 2.04 & 10 & 2.05 & 0.289 & 0.591 & 0.782 & $0.319-1.919$ \\
\hline GACC & 4 & 0.82 & 7 & 1.43 & 1.687 & 0.194 & 0.447 & $0.129-1.550$ \\
\hline$\chi^{2}$ & & & & & 26.144 & & & \\
\hline & & & & & 0.016 & & & \\
\hline
\end{tabular}

\section{Risk analysis}

Subjects carrying the rs3856806T, rs12490265A, rs1797912C, and rs1175543G polymorphisms were marked as (+), while those carrying rs3856806C, rs12490265G, rs1797912A, and rs1175543 A were marked as (-). The results showed that the risk of suffering from MS in the $(+)$ group was 0.267 times higher than that in the $(-)$ group $(\mathrm{OR}$ range $=0.126-0.566$; Table 5).

\begin{tabular}{|c|c|c|c|c|c|c|}
\hline Classification & MS & Control & $\chi^{2}$ & $\mathrm{P}$ & OR & $95 \% \mathrm{CI}$ for OR \\
\hline $\begin{array}{l}\text { rs3856806T rs12490265A } \\
\text { rs1797912C } \mathrm{rs} 1175543 \mathrm{G}(+) \\
\text { rs3856806C } \mathrm{rs} 12490265 \mathrm{G} \\
\mathrm{rs} 1797912 \mathrm{~A} \text { rs1175543A (-) }\end{array}$ & $\begin{array}{l}14 \\
51\end{array}$ & $\begin{array}{l}36 \\
35\end{array}$ & 12.416 & 0.000 & $\begin{array}{l}0.267 \\
1.000\end{array}$ & $0.126-0.566$ \\
\hline
\end{tabular}

\section{DISCUSSION}

The main role of the PPAR $\gamma$ gene is to regulate the formation and differentiation of adipocytes. Numerous genes related to fatty acid transport and metabolism require regulation of the PPAR $\gamma$ gene at the transcriptional level. PPAR $\gamma$ gene polymorphisms are reportedly relevant to the components of MS; however, other studies have shown different results (Hu et al., 2004; Chen et al., 2006; Jaziri et al., 2006; Gaulton et al., 2008; Cho et al., 2009; Gallicchio 
et al., 2009; Matsuo et al., 2009; Bego et al., 2011). Understanding the relationship of the high incidence of MS and PPAR $\gamma$ gene polymorphisms is important for determining the mechanism of MS occurrence and development as well as for identifying molecular markers that could be used for early diagnosis and prognosis.

Currently, studies on rs3856806 are abundant, but those on rs12490265, rs1797912, and rs 1175543 are limited. In this study, we found that the allele frequency of rs $3856806 \mathrm{~T}$ in the Kazakh control group was $17 \%$. This value is close to the allele frequency of rs3856806T in the Australian population (16.3\%; Evans et al., 2001), is higher than that in the South American (13\%; Haseeb et al., 2009), Indian (12.3\%; Costa et al., 2009), and Italian and French populations (13.3\%; Hasstedt et al., 2001), but lower than that among the Han population (21.2\%; Liu et al., 2008). Studies examining the relationship between the rs 3856806 polymorphism and MS suggest that individuals carrying the $\mathrm{T}$ allele show clearly reduced rates of lipid metabolism disorders and high blood pressure, obesity, and diabetes (Chen et al., 2006; Jaziri et al., 2006; Gaulton et al., 2008; Cho et al., 2009; Gallicchio et al., 2009; Bego et al., 2011). We found that the individual risk of MS in the Kazakhs carrying the T allele was 0.694 times higher than that in Kazakhs carrying the $\mathrm{C}$ allele. Therefore, the $\mathrm{T}$ allele may have a protective effect against MS in Kazakhs, which is consistent with the results of previous studies.

The frequency of the rs12490265A allele in the Kazakh control group was 38.52\%. This rate is significantly higher than that reported in a Mexican population (13.0\%; Gaulton et al., 2008). The frequency of the rs $1797912 \mathrm{C}$ allele was $43.24 \%$ in the Kazakh control group, which is similar to that in the Japanese population (42.63\%; Matsuo et al., 2009). The rs $1175543 \mathrm{G}$ allele frequency (38.72\%) was lower than that in Finns $(44.10 \%$; Gaulton et al., 2008). We also found that the rs $12490265 \mathrm{~A}$, rs $1797912 \mathrm{C}$, and $\mathrm{rs} 1175543 \mathrm{G}$ alleles may reduce the risk of MS in Kazakhs, with OR values of $0.745,0.716$, and 0.755 , respectively.

Tai et al. (2004) confirmed that the rs 1801282 and rs3856806 polymorphisms in Singaporeans exhibit linkage disequilibrium. Linkage disequilibrium shows racial differences, and is higher in the Indian $\left(D^{\prime}=0.80\right)$ than in the Chinese $\left(D^{\prime}=0.55\right)$ population. Approximately $70 \%$ of those carrying rs $1801282 \mathrm{G}$ also have rs $3856806 \mathrm{~T}$; these genes may work together in phenotypes related to PPAR $\gamma$ (Doney et al., 2002). In analyzing the linkage disequilibrium of the 4 gene loci of PPAR $\gamma$ in Kazakh people in the current study, rs1797912, rs1175543, and rs12490265 showed strong linkage disequilibrium with rs 1175543 . Thus, genetic recombination occurs very rarely between the 4 sites both in genetic processes and in the production of offspring overall.

Haplotype analysis showed that the 4 loci rs12490265, rs1175543, rs1797912, and rs3856806 could produce 14 and 6 haplotypes (AAAT, GACT, AACC, AGCT, AGAT, GGAC) in the Kazakh MS and control groups, respectively. Both groups contain fewer than 4 cases. Haplotype frequencies were less than $0.8 \%$ (data not shown). The analysis results also indicated that compared with those carrying the common haplotype GAAC, individuals carrying the AGCC and GAAT haplotypes had a significantly lower risk of MS. The haplotypes AGCC and GAAT may have protective effects against MS in the Kazakh population.

The rs3856806T, rs $12490265 \mathrm{~A}$, rs1797912C, and rs1175543G polymorphisms may reduce the risk of MS in Kazakh subjects, with OR values of 0.694, 0.745, 0.716, and 0.755, respectively. Based on our results, the risk of MS in individuals carrying the rs3856806T, rs $12490265 \mathrm{~A}$, rs $1797912 \mathrm{C}$, and rs $1175543 \mathrm{G}$ alleles was 0.267 times higher than in those carrying the rs3856806C, rs12490265G, rs1797912A, and rs1175543A alleles. Hence, synergism may exist among rs3856806, rs12490265, rs1797912, and rs1175543 in Kazakh people suffering from MS. 
In summary, polymorphisms of the PPAR $\gamma$ genes, including rs3856806, rs12490265, rs1797912, and s1175543, are correlated with MS risk. Strong linkage disequilibrium exists between rs 1797912 and rs1175543 as well as between rs12490265 and rs1175543. The AGCC and GAAT haplotypes may reduce the risk of MS among Kazakhs.

MS is the result of numerous combined factors, but its specific pathogenesis remains unclear. This study only analyzed the correlation between genetic polymorphisms of PPAR $\gamma$ and MS among Kazakh subjects in Xinxiang, and only from a genetic standpoint. The complete effect of the PPAR $\gamma$ gene on MS risk remains unclear. In addition, how environmental and behavioral factors affect MS and the roles of genetic factors on the occurrence and development of MS should be further examined.

\section{ACKNOWLEDGMENTS}

Research supported by grants from the National Science and Technology Support Projects for the "Eleventh Five-Years Plan" of China (\#2009BAI82B04) and the International Science and Technology Cooperation Program of Xinjiang Production and Construction Corps (\#2009YD33).

\section{REFERENCES}

Alberti KG, Zimmet P and Shaw J (2005). The metabolic syndrome - a new worldwide definition. Lancet 366: 1059-1062.

Bego T, Dujic T, Mlinar B, Semiz S, et al. (2011). Association of PPARG and LPIN1 gene polymorphisms with metabolic syndrome and type 2 diabetes. Med. Glas. 8: 76-83.

Bouguerra R, Ben SL, Alberti H, Ben RC, et al. (2006). Prevalence of metabolic abnormalities in the Tunisian adults: a population based study. Diabetes Metab. 32: 215-221.

Chen L, Velasco Mondragón HE, Lazcano-Ponce E, Collins A, et al. (2006). Effect of the peroxisome proliferatorsactivated receptor (PPAR) gamma 3 gene on BMI in 1,210 school students from Morelos, Mexico. Pac. Symp. Biocomput. 467-477.

Cho YM, Kim TH, Lim S, Choi SH, et al. (2009). Type 2 diabetes-associated genetic variants discovered in the recent genome-wide association studies are related to gestational diabetes mellitus in the Korean population. Diabetologia 52: $253-261$

Costa V, Casamassimi A, Esposito K, Villani A, et al. (2009). Characterization of a novel polymorphism in PPARG regulatory region associated with type 2 diabetes and diabetic retinopathy in Italy. J. Biomed. Biotechnol. 2009: 126917.

Doney A, Fischer B, Frew D, Cumming A, et al. (2002). Haplotype analysis of the PPARgamma Pro12Ala and C1431T variants reveals opposing associations with body weight. BMC Genet. 3: 21.

Evans D, de Heer J, Hagemann C, Wendt D, et al. (2001). Association between the P12A and c1431t polymorphisms in the peroxisome proliferator activated receptor gamma (PPAR gamma) gene and type 2 diabetes. Exp. Clin. Endocrinol. Diabetes 109: 151-154.

Gallicchio L, Chang HH, Christo DK, Thuita L, et al. (2009). Single nucleotide polymorphisms in obesity-related genes and all-cause and cause-specific mortality: a prospective cohort study. BMC Med. Genet. 10: 103.

Gaulton KJ, Willer CJ, Li Y, Scott LJ, et al. (2008). Comprehensive association study of type 2 diabetes and related quantitative traits with 222 candidate genes. Diabetes 57: 3136-3144.

Gavrila D, Salmerón D, Egea-Caparrrós JM, Huerta JM, et al. (2011). Prevalence of metabolic syndrome in Murcia Region, a southern European Mediterranean area with low cardiovascular risk and high obesity. BMC Public Health 11: 562 .

Grundy SM, Cleeman JI, Daniels SR, Donato KA, et al. (2005). Diagnosis and management of the metabolic syndrome: an American Heart Association/National Heart, Lung, and Blood Institute Scientific Statement. Circulation 112: 2735-2752.

Gu D, Reynolds K, Wu X, Chen J, et al. (2005). Prevalence of the metabolic syndrome and overweight among adults in China. Lancet 365: 1398-1405. 
Haseeb A, Iliyas M, Chakrabarti S, Farooqui AA, et al. (2009). Single-nucleotide polymorphisms in peroxisome proliferator-activated receptor gamma and their association with plasma levels of resistin and the metabolic syndrome in a South Indian population. J. Biosci. 34: 405-414.

Hasstedt SJ, Ren QF, Teng K and Elbein SC (2001). Effect of the peroxisome proliferator-activated receptor-gamma 2 pro(12)ala variant on obesity, glucose homeostasis, and blood pressure in members of familial type 2 diabetic kindreds. J. Clin. Endocrinol. Metab. 86: 536-541.

Hu G, Qiao Q, Tuomilehto J, Balkau B, et al. (2004). Prevalence of the metabolic syndrome and its relation to all-cause and cardiovascular mortality in nondiabetic European men and women. Arch. Intern. Med. 164: 1066-1076.

Jaziri R, Lobbens S, Aubert R, Péan F, et al. (2006). The PPARG Pro12Ala polymorphism is associated with a decreased risk of developing hyperglycemia over 6 years and combines with the effect of the APM1 G-11391A single nucleotide polymorphism: the Data from an Epidemiological Study on the Insulin Resistance Syndrome (DESIR) study. Diabetes 55: 1157-1162.

Jiang S and Xie Z (2012). Comparison study of metabolic syndrome's differences and diagnostic criteria's applicability among Xingjiang Uighur, Kazak and Han Population. Int. J. Endocrinol. 2012: 212383.

Liu DX, Hua Q, Liu LS and Guo JC (2008). Association of peroxisome proliferator-activated receptorgamma gene Pro12Ala and C161T polymorphisms with metabolic syndrome. Circ. J. 72: 551-557.

Matsuo T, Nakata Y, Katayama Y, Iemitsu M, et al. (2009). PPARG genotype accounts for part of individual variation in body weight reduction in response to calorie restriction. Obesity 17: 1924-1931.

Tai ES, Corella D, Deurenberg-Yap M, Adiconis X, et al. (2004). Differential effects of the C1431T and Pro12Ala PPARgamma gene variants on plasma lipids and diabetes risk in an Asian population. J. Lipid. Res. 45: 674-685. 